\section{OBSERVATIONS ON SURGICAL SHOCK}

\section{A PRELIMINARY NOTE *}

YANDELL HENDERSON, Рн.D.

\author{
A. L. PRINCE, M.D. \\ H. W. HAGGARD, M.D. \\ NEW HAVEN, CONN.
}

At the request of the Committee on Physiology of the National Research Council, a cooperative investigation of surgical shock has been instituted in a number of physiologic laboratories throughout the country, and one preliminary report has already been published in ThE Journal. ${ }^{1}$ We have selected as our part in this investigation three problems: (1) the bearing of excessive and prolonged secretion of epinephrin on the production of shock; (2) the relation of acidosis to shock, and (3) the oxidative metabolism in shock.

While pressure of other duties has prevented the completion of these studies, we have obtained data which are of sufficient interest for publication in the form of a preliminary note.

\section{EPINEPHRIN AND SHOCK}

The condition of "surgical shock," unless associated with extensive hemorrhage, is always the result of prolonged and severe sensory stimulation. As stimulation of sensory nerves induces discharge from the suprarenal glands, it may be assumed that the rate and duration of secretion is proportional to the intensity of the stimulus. Whether a prolonged condition of excess of epinephrin in the circulating blood can produce shock is one of the questions we have attempted to decide.

The experiments were conducted under ether anesthesia. Cats and dogs were employed. Respiration and arterial pressure were recorded. Epinephrin (adrenalin chlorid solution, Parke, Davis \& Co.) of various strengths (usually $1: 10$ and from 0.5 to 1 c.c. per minute) were infused into the femoral vein, in some experiments at a constant rate, in others intermittently. The blood pressure was thus maintained at a very high level for a period of from one-half hour to two hours. Then the administration was discontinued. Careful observations were made at frequent intervals during and following the epinephrin administration. In none of the experiments did symptoms of shock appear. The only definite symptoms observed were those of edema of the lungs and acute cardiac dilatation. The majority of our animals died suddenly of the latter cause.

We conclude that prolonged excessive secretion of epinephrin (if it occurs under pain) is not a critically important factor in the production of shock. It is therefore improbable that surgical shock is a result of excessive secretion of the suprarenals secondary to sensory stimulation. ${ }^{2}$

THE RELATION OF ACIDOSIS TO SHOCK

It may be recalled that some years ago a theory of. shock was put forward from this laboratory which assigned the development of the condition largely to

* From the Physiological Laboratory of the Yale University School of Medicine.

1. Pike, F, H., and Coombs, Helen C.: The Relation of Low Blood Pressure to a Fatal Termination in Traumatic Shock, THE Journal A. M. A. June 23, 1917, p. 1892 .

2. Recent observations of Mann (The Journal A. M. A., Aug. 4 1917, p. 371) indicate also that deficiency of epinephrin (excision of suprarenals) does not produce shock. decrease in the carbon dioxid content of the blood resulting from the excessive breathing induced by ether, by pain and by fear. Since that series of papers was published, development of knowledge regarding the relations of carbon dioxid in the blood has been rapid and has laid stress first on alterations of the hydrogen-ion concentration involved and recently on alterations of the alkaline reserve. Any one discovering now for the first time that in shock the blood contains less than the normal amount of carbon dioxid would infer from present conceptions that shock involves acute acidosis. The occurrence of acidosis in connection with shock was in fact recognized in the series of papers referred to above. ${ }^{3}$ It appeared to us important to investigate further the relations of acidosis to shock and to. the excessive breathing induced by pain, and by ether.

Our experiments were carried out on ten dogs. The anesthetics used were ether, morphin, chloral and chloretone (each alone, not in combination). After a control period of from two to three hours under anesthesia, shock was induced by exposing and manipulating the intestines. In all cases the blood pressure, respiration and physical signs were observed. Low arterial pressure and absence of reflexes were taken as indications of shock.

At uniform intervals throughout the experiments, about 5 c.c. of blood were withdrawn from the carotid and collected in a test tube under a layer of liquid petrolatum. Without delay a part of this blood was analyzed for its carbon dioxid content. Another part (whole blood, not serum) was saturated with (human) alveolar air containing about 5.5 per cent. of carbon dioxid and analyzed for carbon dioxid in order to determine the "alkaline reserve" as the index of "acidosis." Samples of alveolar air were collected from the animal at frequent intervals by the HigginsPlesch method, and the alveolar carbon dioxid tension was determined. The methods of blood, gas and alveolar air analysis employed were those described by Henderson and Morriss. ${ }^{4}$ In two experiments the respiratory exchange (oxidative metabolism) was determined by the Douglas bag method.

Morriss $^{5}$ has recently shown that administration of ether induces a fall in the alkaline reserve as determined by the Van Slyke method, and our observations corroborate this. In all of our experiments with (open) ether anesthesia there was during the first hour the usual excessive breathing and a sharp fall both in the carbon dioxid content of the arterial blood and in the carbon dioxid capacity of the blood, followed for several hours thereafter by a less rapid but distinctly progressive and almost parallel fall in both measurements. The alveolar carbon dioxid also followed a closely similar course. There was a corresponding degree of "shock," as judged by fall of arterial pressure and absence of reflexes.

In contrast, in one experiment in which ether was administered by a rebreathing method, we found that when excessive elimination of carbon dioxid was thus in part prevented, both the carbon dioxid content, and the carbon dioxid capacity (alkaline reserve) of the blood as well as the vitality of the subject were much less reduced than under "open" ether conditions."

3. Henderson: Am. Jour. Physiol., 1910, 27, 174

4. Henderson and Morriss: Jour. Biol. Chem, 1917, 31, 217

5. Morriss W. H. The Prophylaxis of Anesthesia Acidosis, Tue Journal A. M. A., May 12, 1917, p. 1191.

6. Bryant, John, and Henderson, Yandell: Closed Ether and a Color Sign, The Journal A. M. A., July 3, 1915, p. 1. 
In the animals under open ether the institution of shock producing procedures had, and indeed could have, little additional effect in producing acidosis, owing to the intensity of this condition already produced by the anesthetic and its mode of administration.

In view of this fact we turned to experiments under morphin (one experiment), chloral hydrate (one), and chloretone (two), since all of these drugs depress respiration and tend to produce a hypercapnia. ${ }^{7}$ In this connection we would call attention to an observation of Underhill, Blatherwick and Goldschmidt, ${ }^{8}$ which seems to us to suggest that morphin (by means of hypercapnia?) causes a mobilization of the body's alkali.

In the experiment under morphin narcosis, there was no fall, indeed a slight rise ( 2 per cent.), in the carbon dioxid content and the carbon dioxid capacity of the blood during a preliminary or control period of two hours. Shock procedures were then instituted and were followed by a rapid and progressive acidosis - the carbon dioxid capacity falling to 31 per cent. together with the usual excessive breathing, fall of arterial pressure, and disappearance of reflexes, ending in death after two hours.

In an experiment under chloretone anesthesia, the carbon dioxid capacity of the blood fell during the preliminary period of three hours only from 48 (practically normal for a $\operatorname{dog}$ ) to 43 per cent. Shock was then induced. One and one half hours latcr the carlon dioxid capacity of the blood had fallen to 30 volumes per cent. The animal died half an hour. later.

These observations raise a crucial question as to the nature of the relation between the hyperpnea of ether excitement and of pain and the accompanying decrease of carbon dioxid combining power in the blood. Which is cause and which is effect? The acapnia theory assigned a primary rôle to the hyperpnea, while the acidosis theory now current would make the hyperpnea merely secondary. Does the alkali of the bicod control the carbon dioxid or the carbon dioxid the alkali? In most forms of acidosis the former is the case. In shock, however, the latter may in part at least be the true sequence. It may be recalled that in experiments on shock previously reported from this laboratory it was found that when excessive loss of carbon dioxid was prevented by rebreathing procedures. the carbon dioxid content of the blood was only slightly lowered, and shock either did not result or was much reduced in intensity. These facts suggest that the acidosis of ether anesthesia is compensatory to or a result of the acapnia produced by the hyperpnea of ether excitement.

Apparently the reduction of the carbon dioxid content of the blood by the excessive breathing under pain or ether excitement results either in loss of alkali (to the tissues $\left.{ }^{\prime}\right)$ or a formation or retention of other acids. This acidosis, or reduction of alkaline reserve, whatever its cletails, is at least in respect to respiration clearly of a compensatory character, for otherwise the intense acapnia would always quickly result in a fatal apmea, as in fact it often does. It is particularly noteworthy in support of this conception that in the experiment with ether in which the animal was made to rebreathe through a long tube, thus keeping the alveolar carbon dioxid tension at a nearly normal level, the rate and degree of ether acidosis were correspondingly decreased.

7. Henderson and Scarbrough: Am. Jour. Plysiol. 1910, 26. 274. 8. Underhill, Blatherwick and Goldschmidt: Proc. Soc. Exper. Bicl. and Med., 1917, 14, 83.
THE OXIDATIVE METABOLISM IN SHOCK

In the metabolism experiments in which observations of the oxygen consumption and carbon dioxid elimination were made before and after the production of shock, we found that the condition of shock involves a profound depression of metabolism, the oxygen consumption falling 45 per cent. in one experiment and 50 per cent. in another. This depression of metabolism is progressive, and ends in death.

The introduction of the gas mask in warfare has accustomed men to a form of apparatus with which rebreathing can be readily arranged. Fortunately it is easily applicable on the only field where sufficient human material is regularly available for the study of shock. By this means we hope to be able at last to get an adequate test of the very practical question, Will rebreathing prevent or decrease the development of shock in severely wounded men as it does in animals under experimental conditions?

For those already in shock and breathing feebly, rebreathing involves a dangerous limitation of oxygen. In this condition, the administration of percentages of carbon dioxid approximating the normal alveolar air (by the same method that oxygen is usually given) is the measure which in the light of ten years' work in this laboratory is certainly worthy of trial.

\section{BOTULISM}

\section{THE DANGER OF POISONING FROM VEGETABLES CANNED BY THE COLD-PACK METHOD *}

\section{ERNEST C. DICKSON, M.D.}

$$
\text { SAN FRANCISCO }
$$

The frequency with which food poisoning is caused hy the presence of the toxin of the Bacillus botulinus is probably very much greater in this country than has been generally believed, and the fact that the toxin may be formed not only in foods of animal origin but also in certain vegetables and fruits has added much to the importance of recognizing its existence.

A review of the available American medical literature for the past twenty years has shown that there have been at least eleven recorded outbreaks of botulism in the United States during that time, and that a least fifty-two persons have been ill and thirtytwo have died from this type of food poisoning.

In a personal investigation ${ }^{1}$ of unrecorded cases of food poisoning which have occurred on the Pacific Coast during the past six years, I have located eleven more outbreaks of botulism in which twenty-nine persons were ill and twenty-three died, and in three of these I succeeded in establishing the diagnosis of botulism by the isolation of the $B$. botulinus from portions of the discarded food. In all, therefore, there have been at least twenty-two known outbreaks of botulism in the United States during the past twenty years (Table 1) in which eighty-one persons have been ill and fifty-five have died, a mortality of 67.9 per cent.; and of these twenty-two outbreaks, eighteen have occurred on the Pacific Coast, seventeen in California, and one in Oregon. It is extremely probable that there have been many more outbreaks of botulism

* Aided by a grant from the California State Council of Defense. * From the Division of Medicine of the Leland Stanford Junior Unirersity School of Medicine.

1. The details of the clinical cases and of the experimental work will appear shortly in a monograph entitled "Botulism: A Clinical and 